\title{
Clinical Management of Critical COVID-19 Patients: Insights from the Literature and "On the Field" Experience
}

\author{
Francesco Alessandri ${ }^{1, *}$ Federico Bilotta ${ }^{1,{ }^{*}}$ Giancarlo Ceccarelli ${ }^{2}$ Franco Ruberto ${ }^{1}$ Fabio Araimo ${ }^{1}$ \\ Carmela Imperiale ${ }^{1}$ Francesco Pugliese ${ }^{1}$ for the PolU COVID-19 Team
}

1Department of Anesthesia and Intensive Care Medicine, "Sapienza" University of Rome, Policlinico Umberto I, Rome, Italy

${ }^{2}$ Department of Public Health and Infectious Diseases, University of Rome Sapienza, Policlinico Umberto I Rome, Rome, Italy

Neuroanaesthesiol Crit Care 2020;7:54-61

\begin{abstract}
Address for correspondence Federico Bilotta, MD, Department of Anesthesia and Intensive Care Medicine, "Sapienza" University of Rome, Policlinico Umberto I, Viale del Policlinico 155, 00161 Rome, Italy (e-mail: bilotta@tiscali.it).
\end{abstract}

\begin{abstract}
Keywords

- clinical management

- COVID-19 patients

- "on the field"

experience

The recent outbreak of the coronavirus disease (COVID-19) is a health emergency all over the world. Several health care professionals are currently putting their best efforts to deal with this situation. The aim of this review is to report insights from the literature and "on the field" experience in clinical management of critical COVID-19 patients. Respiratory support varies from high flow nasal cannula (HFNC) to noninvasive and invasive mechanical ventilation, often associated with nitric oxide, prone position, and extracorporeal membrane oxygenation (ECMO). Experienced specialists have to manage the airways minimizing any contamination and virus spread. The hemodynamic management of critical COVID-19 patients requires not only an accurate fluid strategy, but also an appropriate use of vasopressors and inotropes. Various adjuvant treatments have been proposed: antiviral drugs, immunomodulators, anticoagulants, antibiotics, and nutrition.
\end{abstract}

\section{Introduction}

At the end of 2019 in Wuhan, China, a novel coronavirus, formally named as severe acute respiratory syndrome coronavirus 2 (SARS-CoV2), was identified as the causative pathogen of a coronavirus disease (COVID-19) that presents as bilateral interstitial pneumonia. ${ }^{1}$ This SARS-CoV2 is a major threat to public health: as of April 21,2020, worldwide death toll exceeds 175,812 casualties, and there have been 2,546,527 confirmed cases with growing incidences. ${ }^{2}$ The source of SARS-CoV2, a positive

\footnotetext{
* These two authors contributed equally to the paper. Group Information: The Policlinico Umberto I COVID-19 (PoLU COVID-19 Team) Members: Pugliese Francesco, MD, Bilotta Federico, MD, Alessandri Francesco, MD, Ruberto Franco, MD, Araimo Fabio, MD, Imperiale Carmela, MD, Albante Alida, MD, Auricchio Daniela, MD, De Lazzaro Francesco, MD, De Lauri Daniela, MD, Di Santo Carmela, MD, Ianni Stefano, MD, Magnanimi Eugenia, MD, Ratini Fabiola, MD, Sabani Anna, MD, Titi Luca, MD, Vaccaro Paola, MD, Giordano Giovanni, MD,
}

sense ribonucleic acid (RNA, 26-32 kilobases) genome virus of the family Coronaviridae, has been determined as bats to bats coronavirus with a $96 \%$ identical whole-genome. ${ }^{3}$ The disease is transmitted largely by inhalation of respiratory droplets, but the contagion can spread by contact with infected surfaces and mucous membrane. ${ }^{4}$ Patients older than 60 years are at higher risk than younger ones: children may show milder symptoms or even asymptomatic infection. A gender predisposition exists, with higher incidence in men than in women. ${ }^{5}$ Among adult

Manganelli Chiara, MD, Mancone Massimo, MD, Bruno Katia, MD, Celli Paola, MD, Consolo Stella, MD, Croce Claudia, MD, Giannetti Lorena, MD, Martelli Sabina, MD, Messina Teresa, MD, Pattelli Elisa, MD, Perrella Serena, MD, Piazzolla Mario, MD, Portieri Monica, MD, Ricci Claudia, MD, Almenrader Nicole, MD, Arzilla Roberto, MD, Delia Emilia, MD, Di Giovanni Claudio, MD, Macrì Carlotta, MD, Marandola Maurizio, MD, Nardecchia Giada, MD, Pacilli Massimo, MD, Pacini Francesca, MD, Tordiglione Paolo, MD
DOI https://doi.org/ $10.1055 / \mathrm{s}-0040-1713016$ ISSN 2348-0548.
License terms

(우 (1) $\ominus \circledast$ 
patients who develop COVID-19, cardiovascular disease and hypertension are the most common associated comorbidity, followed by diabetes mellitus. ${ }^{6,7}$ The median incubation period is 5 days (range: $2-14) .{ }^{8}$ The proportion of individuals infected by SARS-CoV2 who remain asymptomatic throughout the course of infection has not yet been definitely assessed..$^{9}$ Initial clinical presentation of COVID-19 is characterized by symptoms of upper respiratory tract infections with fever, dry cough, nasal congestion, fatigue, and headache; recent studies reported gastrointestinal symptoms. ${ }^{10}$ The infection can progress in 2 weeks to a severe pneumonia with dyspnea, chest symptoms, and impairment of gas exchanges with severe hypoxic respiratory failure and acute respiratory distress syndrome (ARDS). ${ }^{10}$ Approximately 40\% of severe COVID-19 patients may present with neurological manifestations (-Table 1). ${ }^{11,12}$ Bilateral infiltrates appear at the chest X-rays, and computed tomography (CT) scans show ground glass abnormalities, patchy consolidation, alveolar exudates, and interlobular involvement, though no radiographic or CT abnormality was found in up to $18 \%$ of patients with nonsevere disease. ${ }^{13,14}$ Lung ultrasound is strongly suggested as diagnostic and monitoring tool to detect subpleural consolidation and lung interstitial syndrome pattern before development of hypoxemia. ${ }^{15}$ Leukopenia and lymphopenia are common and related to a worst prognosis. Inflammatory markers (C-reactive protein, fibrinogen, and proinflammatory cytokines) are elevated. Liver enzymes (alanine aminotransferase, aspartate aminotransferase), lactate dehydrogenase, creatinine kinase, and D-dimer levels are increased, while platelet count is low. ${ }^{7}$ Evidence and individual experience in the treatment of critical COVID-19 patients are evolving in real time, and the extensive reorganization of hospital resources often involve human resources and professionals who are generally dedicated to specific subspecialties as neuroanesthesiologists and neurointensivists.

The aim of this review is to report insights from the literature and "on the field" experience in clinical management of critical COVID-19 patients. Information on respiratory support, fluid therapy, hemodynamic adjuvant treatments, and nutrition will be included.

\section{Respiratory Support}

Oxygen therapy is indicated in patients who present with peripheral blood oxygen saturation $\left(\mathrm{SpO}_{2}\right)<90 \%$ and is

Table 1 Nervous system symptoms

\begin{tabular}{|l|}
\hline Central nervous system \\
\hline Dizziness \\
\hline Headache \\
\hline Impaired consciousness \\
\hline Acute cerebrovascular disease \\
\hline Ataxia \\
\hline Seizure \\
\hline Peripheral nervous system \\
\hline Impairment taste, smell, vision \\
\hline Nerve pain \\
\hline Skeletal muscle injury \\
\hline
\end{tabular}

necessary in $14 \%$ of hospitalized patients, while $5 \%$ of these develop a severe acute respiratory failure that impose mechanical ventilation. ${ }^{16}$ The fraction of $\mathrm{O}_{2}$ delivered should be titrated to maintain $\mathrm{SpO}_{2}$ at 92 to $96 \% .{ }^{17}$ Acute respiratory failure in COVID-19 is due to an interstitial bilateral pneumonia that can rapidly evolve into severe ARDS. Considering the short timeline of clinical deterioration presented in some patients, it is necessary to warrant appropriate monitoring for those with symptomatic hypoxia $\left(\mathrm{SpO}_{2} /\right.$ fraction of inspired oxygen $\left[\mathrm{FiO}_{2}\right]$ ratio, respiratory rate, etc.). ${ }^{18}$ Current clinical practice is based, at the most, on evidence collected in ARDS caused by other pathogens and not specifically suited for COVID-19, and is therefore nonspecific and continuously evolving. ${ }^{19}$ Treatment includes noninvasive support with high flow nasal cannula (HFNC), noninvasive and invasive ventilation, and-in selected cases-rescue ventilatory therapies that include prone position (PP), use of inhaled nitric oxide (iNO), and extracorporeal membrane oxygenation (ECMO).

\section{High Flow Nasal Cannula}

HFNC provides oxygen more effectively with the use of $\mathrm{FiO}_{2}$ up to 1.0 and fresh gas flow ranging from 30 to $60 \mathrm{~L} / \mathrm{min}$. The improvement in partial pressure of oxygen $\left(\mathrm{PaO}_{2}\right)$ and the associate reduction of "dead space" facilitates $\mathrm{CO}_{2}$ washout with lower positive end-expiratory pressure (PEEP) levels, which allows to optimize, at the most, the ventilation in spontaneously breathing patients and minimizes the cardiovascular impact of ventilator support. ${ }^{20}$ Whether health care professionals, exposed to HFNC, are at an increased risk of developing the disease is not entirely clear. ${ }^{21,22}$ This approach, so long supported by limited published evidence, in our experience reduces the number of patients that requires intubation and invasive mechanical ventilation. In a previous study, functional residual capacity of patients treated with HFNC combined with awake PP was assessed with electrical impedance tomography; patients in PP showed a more homogeneous distribution of end-expiratory lung impedance $(\Delta \mathrm{EELI})$ than in supine position. ${ }^{23}$ Some patients hospitalized in our department were treated with HFNC combined with awake PP and this successfully increased dorsal lung recruitment. In a rapidly evolving pandemic, the effort to save and optimize limited resources-such as the use of mechanical ventilators and intensive care unit (ICU) beds-has a great importance and can ultimately increase the overall survival rates.

\section{Noninvasive Ventilation}

Noninvasive ventilation (NIV) has been effectively applied in different respiratory failure settings, like chronic obstructive pulmonary disease exacerbations or cardiogenic pulmonary edema, reducing muscular fatigue, the need of endotracheal intubation, the rate of ventilator-associated complications, and mortality. ${ }^{24}$ However, in acute hypoxic respiratory failure like pneumonia and ARDS, the level of evidence is low. ${ }^{25}$ In adults with COVID-19 and acute hypoxemic respiratory failure, if HFNC is not available and there is no urgent indication for endotracheal intubation, an early support trial with NIV or continuous positive airway pressure is suggested. ${ }^{20}$ Helmet is commonly considered more comfortable than mask, 
especially when continuous support is required. ${ }^{26}$ A close monitoring of respiratory rate and $\mathrm{SpO}_{2}$ is recommended to avoid any delay in threatening acute respiratory worsening. ${ }^{20}$ Furthermore, the role of an assisted ventilation mode could be potentially counterproductive because of the risk of overinflated lung, when patients generate high negative intrathoracic pressures (patient "self-inflicted" lung injury). ${ }^{27}$ Despite inconclusive evidence, a hidden and unmeasured superimposed level of transpulmonary pressure increases lung inflammation and biotrauma or barotrauma. It is now also clear that in patients in whom increasing levels of PEEP are used, lung overdistension induces a hemodynamic impairment. ${ }^{28}$

\section{Intubation}

Appropriate procedures for COVID-19 patients' intubation should be designed to effectively provide optimal care to the patients along with adequate protection of the involved health care providers in settings that in some cases are suboptimal due to the high rate of case load. ${ }^{29,30}$ It is recommended that when intubation is required, rapid sequence anesthesia induction should be accomplished immediately after preoxygenation while the patient is spontaneously breathing to warrant the best possible oxygen reserve. Preventilation through a "to and fro" circuit should be avoided or limited to reduce virus aerosolization (-Fig. 1). Furthermore, experienced health care provider should be selected, to be effective at the first attempt. The use of videolaryngoscope is recommended, and no more than a second operator should assist to minimize the risk of virus contamination; intubation under a plastic sheet or airway box could be useful to minimize aerosolization. ${ }^{31}$ During fast-track induction, hypnotic drugs and neuromuscular blocking agent should be at an appropriate dose and injection rate to provide the fastest loss of consciousness and to prevent-at the most-a drop in arterial blood pressure. In case of unpredicted difficult intubation, percutaneous cricothyrotomy should be early considered.

\section{Invasive Mechanical Ventilation}

Although the clinical features of a severe ARDS are proved by an acute refractory hypoxemia and bilateral infiltrates at the chest imaging, most of the COVID-19 patients present high respiratory compliance with plateau pressures $\left(P_{\text {plat }}\right)$ that does not exceed $30 \mathrm{cmH}_{2} \mathrm{O}$. Extensive intrapulmonary shunt and the loss of lung perfusion regulation along with hypoxic pulmonary vasoconstriction have been reported as possible underlying mechanisms. ${ }^{29}$ Available guidelines recommend to use protective ventilation with low tidal volume of $6 \mathrm{~mL} / \mathrm{kg}$ of predicted body weight and a $P_{\text {plat }}$ limited to $30 \mathrm{cmH}_{2} \mathrm{O}$, inspiratory flow $50-70 \mathrm{~L} / \mathrm{min}$ with end-of-breath pause of 0.2 to 0.5 second, inspiratory:expiratory (I:E) ratio from $1: 1$ to $1: 3$, respiratory frequency of 20 to $35 \mathrm{breath} / \mathrm{min}$, and to maintain a $\mathrm{pH}$ of 7.3-7.5. If the $\mathrm{pH}$ is $<7.30$, the respiratory frequency should be increased up to $35 / \mathrm{min}$; if the $\mathrm{pH}$ is $>7.5$, the respiratory rate should be progressively reduced to the target $\mathrm{pH}$ range. In mechanically ventilated patients, the target $\mathrm{SpO}_{2}$ should be set to attain values in the 92 to 95\% range; therefore, optimal $\mathrm{FiO}_{2}$ and PEEP should be determined aiming to avoid hemodynamic consequences with PEEP-induced reduction of cardiac output. In our experience, the used PEEP value is determined driven not only by lung compliance but also by including the balance between optimizing oxygenation and the best lung

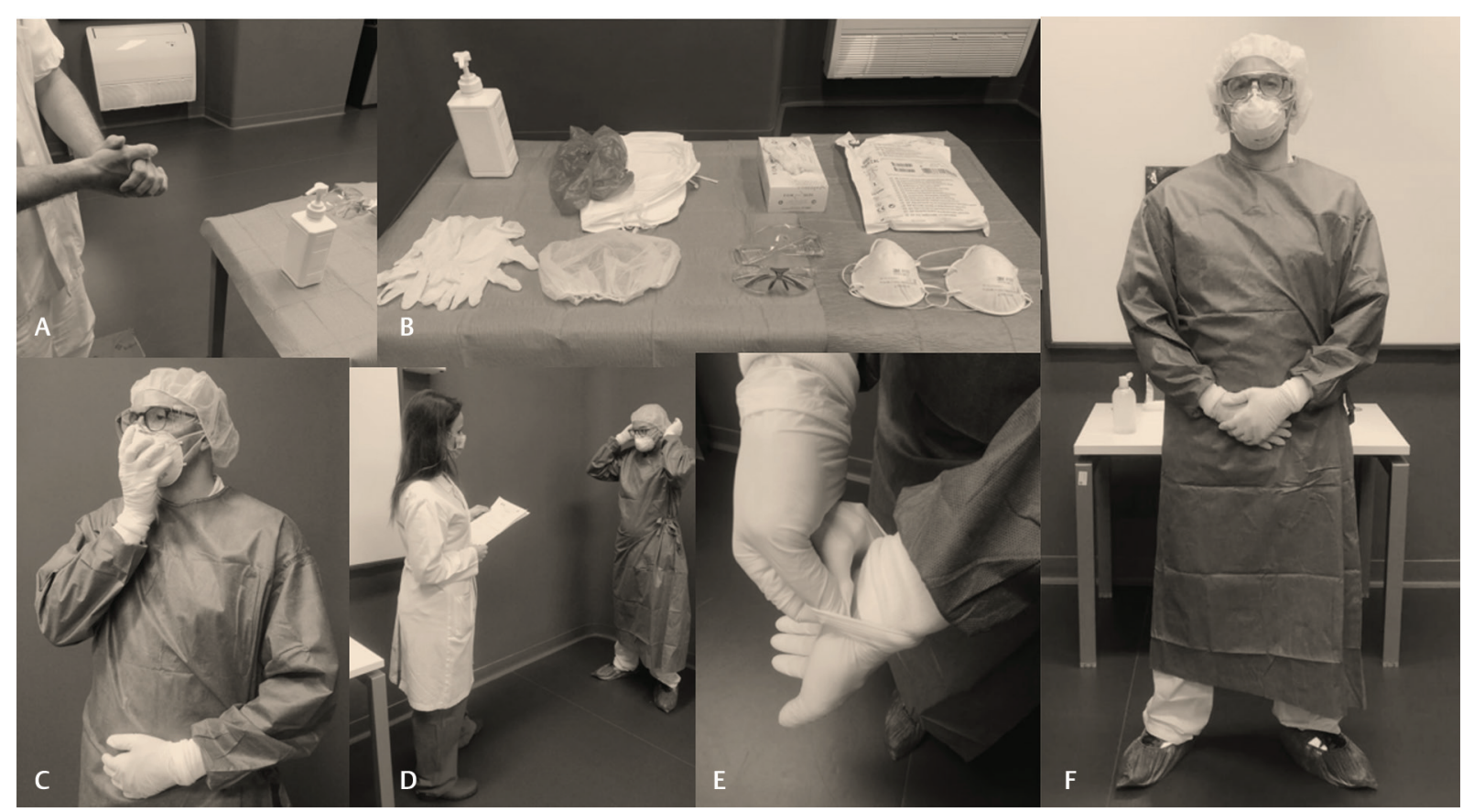

Fig. 1 Donning and doffing personal protective equipment (PPE) for aerosol-generating procedures. (A) Donning begins by hands cleaning with hand sanitizer. (B) PPE include alcohol-based hands sanitizer, gowns, two pairs of gloves, medical mask and eye protection (goggles or face shield), and shoe covers. (C) Apply the face mask safely and fit flexible band to nose bridge and check that breathing is filtered by the mask. (D) Doffing is accomplished under the guidance of a dedicated operator. (E) Gloves are removed preserving underneath sterility (F) Health care provider ready to work. 
perfusion that associates with stable hemodynamic conditions. Peak PEEP values limited to 10 to $12 \mathrm{cmH}_{2} \mathrm{O}$ are now used in several Italian centers. ${ }^{32,33}$

\section{Rescue Ventilator Therapies}

In patients with ARDS, several rescue ventilator therapies have been tested to "buy time" to blunt the inflammatory response and to facilitate the reaction of the immune system; these include PP, iNO, and ECMO. ${ }^{34}$

The use of PP in moderate-severe ARDS patients with $\mathrm{PaO}_{2} /$ $\mathrm{FiO}_{2}<150 \mathrm{~mm} \mathrm{Hg}$, a ventilation strategy optimizing ventilation/ perfusion mismatch $(\mathrm{V} / \mathrm{Q})$ and improving dorsal lung recruitment after at least 12 to 16 hours has been proven to be effective by PROSEVA. ${ }^{35}$ In patients with COVID-19 who present with ground glass opacities and predominantly basilar consolidation in the posterior lung parenchyma, PP is indicated by current guidelines. ${ }^{20}$ As reported in the literature and according to our experience, in patients with high pulmonary compliance, the long-term clinical benefits of this strategy is limited..$^{32}$ This is a relevant aspect considering the high work load and health care resource utilization needed to realize PP. ${ }^{36,37}$ Furthermore, the health care providers involved in PP need appropriate training to minimize the associated complications such as displacement of vascular lines and endotracheal tube, pressure sores, facial edema, corneal abrasions, brachial plexus injury. ${ }^{36,37}$

Experience on the use of iNO and ECMO in COVID-19 patients is extremely limited. Routine use of iNO is discouraged; it should be tested on patients who present refractory severe hypoxia, and if ineffective should be gradually down-titrated and progressively stopped. ${ }^{20}$ Clinical experience with ECMO in COVID-19 patients is very limited. In our center, it has been used with a "compassionate approach" based on the experience gathered in ARDS patients. The limited results collected so long do not allow to draw final conclusions, and ECMO use should be limited to extremely serious patients to be referred to specialized centers. ${ }^{38,39}$

\section{Fluid Therapy and Hemodynamic Management}

Perfusion is a key point in the pathogenesis of septic shock and inflammation. Although the pathophysiological mechanisms leading to organ failure during sepsis remain poorly understood, the impairment of tissue perfusion is a key point in inflammation during septic shock. Alterations of microcirculatory perfusion are associated with organ failure severity and mortality in systemic inflammatory response syndrome and septic shock patients. ${ }^{40}$

Optimization of the hemodynamic conditions in critical COVID-19 patients is of paramount importance considering that at hospital admission they often present with severe dehydration and hypovolemia associated with reduction of cardiac output that can be further aggravated by the use of high PEEP values. ${ }^{41}$ The ARDS Network secondary analysis and a recent metanalysis on conservative versus liberal fluid management have not demonstrated differences in mortality rate when either approach is used. ${ }^{42,43}$ The same study proved that patients treated with "conservative" strategy had more ventilator-free days and shorter ICU stays than patients assigned to "liberal" fluid management. To keep lungs "dry" while maintaining organ perfusion is the optimal target fluid therapy in ARDS and in the approach currently indicated by literature evidence and followed in our center. Lack of specific recommendations for COVID-19 patients imposes to follow the fluid therapy general management guidelines for critically ill patients: buffered/balanced crystalloids are preferred over unbalanced crystalloids and saline $0.9 \%$ solution is the reference option in limited resources environment. ${ }^{20}$ Use of hydroxyethyl starches is contraindicated for the possible additional risk of renal function impairment and higher mortality. Aggressive fluid administration may worsen ventricular function especially in patients with severe ARDS as acute myocardial infection and myocarditis are common during severe influenza $A$ or B virus infection. ${ }^{4-46}$ Acute kidney injury was uncommon in COVID 19. SARS-CoV2 infection does not aggravate chronic kidney disease in uncommon in COVID-19, and in 116 patients admitted in an infectious disease Chinese department, but no data are referred for patients in ICU Delete this highlight. ${ }^{47}$ In our center, we too noticed an early rise in creatinine and urea that could be associated to the cytokine lung-kidney crosstalk with an important impairment of renal function and need of renal replacement therapy. ${ }^{48,49}$

The use of vasopressors and inotropic agents is necessary when mean arterial blood pressure is $<60 \mathrm{~mm} \mathrm{Hg}$ and organ perfusion is compromised. Norepinephrine is the vasopressor agent of choice for patients with shock. Combined strategy with vasopressin can be suggested to reduce the dose of norepinephrine. Dobutamine is the inotropic drug in case of low cardiac output. Low-quality evidences concern corticosteroids therapy to reverse refractory shock..$^{20}$ Ultrasound-dynamic serial evaluation of the global cardiac function is easy, cheap, noninvasive, and bedside. It is useful to set the right continuous monitoring tool for COVID-19 patient assessment. Central venous oxygen saturation sampled at the edge of the venous central line is a measure of cellular metabolism and its impairment. Swan-Ganz catheter is an invasive device able to collect different information about pulmonary pressures, systemic and pulmonary resistances, cardiac index, aerobic metabolism, and mixed venous oxygen saturation. ${ }^{41,50}$

\section{Adjuvant Treatment and Nutrition}

Antiviral agents, various immunomodulators (interleukin 6 [IL-6] inhibitors, steroids, chloroquine, plasma transfusion), antibiotics, and thromboprophylaxis therapies have been administrated to support the immune function and to prevent complications. ${ }^{51}$ Appropriate nutrition plays a meaningful role in immunomodulation therapy and therefore should be considered among the prescribed treatments.

\section{Antiviral Drugs}

Several classes of antiviral drugs have been tested. Lopinavir is a protease inhibitor that blocks viral replication while 
Ritonavir enhances Lopinavir levels inhibiting its CYP3Adependent metabolism. A combination of Lopinavir and Ritonavir contributes to improve clinical condition of SARS-CoV patients and might be an option in COVID19 infections; however, the benefits are associated to an early use. ${ }^{52}$ Remdesivir inhibits RNA-dependent RNA polymerase complex and shows a broad-spectrum antiviral activity against several RNA viruses with great potential to treat coronavirus, but no conclusive evidence has been yet proven..$^{53}$ Other antivirals such as neuraminidase inhibitors (oseltamivir, peramivir, zanamivir, etc.) or antiviral nucleoside analogues (ganciclovir, acyclovir, and ribavirin) commonly used during influenza have not been proven beneficial in COVID-19 patients. ${ }^{51}$ The use of antivirals in our ICU, also considering specific evidences are lacking, is limited in patients who present with liver impairment and metabolic acidosis possibly related to cytochrome interference.

\section{Immunomodulators}

In the considerable release of proinflammatory cytokines, IL-6 might play a key role; interfering with IL-6 inflammatory cascade seems to provide a potentially beneficial therapeutic approach in critical COVID-19 patients. Tocilizumab, a humanized anti-interleukin-6-receptor (IL-6R) monoclonal antibody that inhibits IL-6 signaling and is commonly used as treatment in rheumatoid arthritis, has been successfully tested on COVID-19 patients. ${ }^{54,55}$ The use of steroids in patients with COVID-19 is not routinely recommended and there is evidence of associated lung injury. ${ }^{56}$ However, in hyperinflammation syndrome, associated to some viral infections, immunosuppression is likely to be beneficial and could reduce mortality. ${ }^{57}$ Chloroquine, an established antimalarial drug, has been proposed to block viral infection by a pH-dependent inhibition of several virus replication like SARS-CoV; it seems to interfere with glycosylation of cellular receptors of SARS-CoV and has immunomodulatory effects, suppressing the production/release of tumor necrosis factor- $\alpha$ and IL-6. Available clinical evidences on chloroquine are based on nonrandomized studies and its use in routine treatment remains controversial. ${ }^{58}$ Infusion of convalescent plasma containing neutralizing antibody in a case series of five patients was recently published showing encouraging improvements in their clinical status, but further investigation needs to define this treatment. ${ }^{59}$

\section{Antibiotics}

The use of antibiotic treatment is often necessary for prophylactic and therapeutic reasons. Associated to other therapies, antibiotics are indicated not only to prevent superinfections, but also some of them have a recognized antiviral effect, concurring to block the viral ingress. Teicoplanin, a glycopeptide antibiotic, provides promising prospective for the prophylaxis and treatment of SARSCoV2 infection-since it could prevent the entry of some envelope pseudotyped viruses into the cytoplasm and inhibits the effects on transcription- and replication-competent virus-like particles. ${ }^{60}$ Azithromycin is active in vitro against different viruses and prevents severe respiratory tract infections. ${ }^{61}$ In a recent study, the association treatment of azithromycin with hydroxychloroquine was significantly more efficient in reducing viral load than hydroxychloroquine alone, with particular caution to QT prolongation. ${ }^{62}$

\section{Anticoagulants and Thromboprophylaxis}

Thrombocytopenia, prolongation of the prothrombin time [PT]/international normalized ratio, partial thromboplastin time, elevation of D-dimer, and decrease in fibrinogen levels are common laboratory markers in COVID-19 patients. Excess thrombin generation and fibrinolysis shutdown, which indicated a hypercoagulable state in patient with infection, induced disseminated intravascular coagulation (DIC). A higher D-dimer and PT on admission are associated with poor prognosis in patients with COVID-19. ${ }^{63}$

Despite effectiveness, anticoagulant therapy for sepsisassociated DIC is still controversial. Low-molecular-weight heparin (LMWH) is the most commonly used anticoagulant in our hospital for preventing DIC and venous thromboembolism in patients. Prescribed LMWH is $100 \mathrm{U} / \mathrm{kg} / \mathrm{day}$ in patients with normal renal function and is reduced in those that present renal impairment. Antithrombosis prophylaxis and the associated clinical effects should be monitored cautiously to avoid extremes such as bleeding or thrombosis. ${ }^{63,64}$

\section{Nutrition}

The immunomodulatory effect of the wide lymphoid bowel tissue in the human body is meaningful, and artificial nutrition has to be considered as a priority in the therapeutic strategy. Artificial nutrition should be started within 72 hours after admission, whenever expected to last longer than 48 hours, and tailored to patient's needs. Enteral nutrition is, whenever feasible, the preferred choice. Daily calorie requirement should be reached within 48 hours, otherwise the combined use of enteral and parenteral nutrition is indicated. Calories should be divided according to the needs of the critically ill, as usually prescribed in patients with pneumonia: protein $3 \mathrm{~g} / \mathrm{kg} /$ day, carbohydrates $2 \mathrm{~g} / \mathrm{kg} /$ day, and lipids $1.5 \mathrm{~g} /$ $\mathrm{kg} /$ day. Immunonutrients such as arginine, nucleotides, or glutamine $\omega-3$ fatty acid could have a role in reducing systemic inflammation and the level of cytokines, but further investigations are needed. The use of probiotics as support treatment is indicated to improve tolerance to enteral feeding, to normalize gut microbiota, and to prevent bacterial translocation. ${ }^{65,66}$

\section{Discussion}

In this "real time" review are reported insights from the literature and from "on the field" experience in the clinical management of critical COVID-19 patients. Relevant aspects of airway management and mechanical ventilation 
strategies, hemodynamic and fluid therapies, adjuvant treatments, and nutritional recommendations are presented. Guidelines available on COVID-19 are mostly based on evidence acquired for similar diseases and are rapidly evolving. Italy is the first developed country that faced a rapid spread of SARS-CoV2 pandemic and the experience in the north part of the country proves that numerous patients required ICU treatment. ${ }^{67}$ Out of 1,591 patients included in a study, 1,287 (99\% [95\% confidence interval, 98-99\%]) needed respiratory support, 1,150 (89\%) received mechanical ventilation, and 137 (11\%) received NIV. The median PEEP was 14 (interquartile range [IQR], 12-16) cm $\mathrm{H} 2 \mathrm{O}$, and $\mathrm{FiO}_{2}$ was greater than $50 \%$ in $89 \%$ of the patients. The median $\mathrm{PaO}_{2} / \mathrm{FiO}_{2}$ was 160 (IQR, 114-220). ${ }^{67}$

Presented indications are consistent with literature published since the beginning of COVID-19 outbreak and with the experience in our center. Research and experience on SARS-CoV2 are ongoing, and the optimal treatment for COVID-19 patients is not completely clear at the moment we are writing this paper. The strength of our experience is based on everyone's work and on the tight attention to details, which is-at large-the essence of daily effort in the clinical management of ICU patients. Of great importance is the multidisciplinary approach and the teamwork. Several professionals are involved and include emergency physician, intensivist, anesthesiologist and infectious disease specialists, pneumologists or pulmonologists, cardiologists, and the other health care providers. At the Policlinico Umberto I, we have organized a pool of professionals-the "COVID-19 team"-to ensure the best possible assistance and harmonized work as in an orchestra. This approach allowed us to face all together this extraordinary event.

In conclusion, the spreading of COVID-19 pandemic infection associates with a steep increase in patients presenting with critical clinical conditions and who require advanced and intensive care support. The extensive hospital reorganization involved various professionals' competences that are usually selectively dedicated to specific subspecialties, including neuroanesthesiologists and neurointensivists. Insights for clinical management presented in this review can provide a background and easily accessible workup for anesthesiologists and intensivists called to respond to a worldwide health care emergency.

\section{Conflict of Interest}

None declared.

\section{References}

1 Huang C, Wang Y, Li X, et al. Clinical features of patients infected with 2019 novel coronavirus in Wuhan, China. Lancet 2020;395(10223):497-506

2 Coronavirus COVID-19 outbreak: latest news, information and updates. Available at: https://www.pharmaceutical-technology.com/special-focus/covid-19/coronavirus-covid-19-outbre ak-latest-information-news-and-updates/. Accessed April 21, 2020

3 Zhou P, Yang XL, Wang XG, et al. A pneumonia outbreak associated with a new coronavirus of probable bat origin. Nature 2020;579(7798):270-273
4 Lin L, Lu L, Cao W, Li T. Hypothesis for potential pathogenesis of SARS-CoV-2 infection-a review of immune changes in patients with viral pneumonia. Emerg Microbes Infect 2020;9(1):727-732

5 Yang X, Yu Y, Xu J, et al. Clinical course and outcomes of critically ill patients with SARS-CoV-2 pneumonia in Wuhan, China: a single-centered, retrospective, observational study. Lancet Respir Med 2020;8(5):475-481

6 Munster VJ, Koopmans M, van Doremalen N, van Riel D, de Wit E. A novel coronavirus emerging in China-key questions for impact assessment. N Engl J Med 2020;382(8):692-694

7 Li Q Guan X, Wu P, et al. Early transmission dynamics in Wuhan, China, of novel coronavirus-infected pneumonia. N Engl J Med 2020;382(13):1199-1207

8 Wang $\mathrm{D}, \mathrm{Hu} \mathrm{B}, \mathrm{Hu} \mathrm{C}$, et al. Clinical characteristics of 138 hospitalized patients with 2019 novel coronavirus-infected pneumonia in Wuhan, China. JAMA 2020;323(11):1061-1069

9 Chang D, Lin M, Wei L, et al. Epidemiologic and clinical characteristics of novel coronavirus infections involving 13 patients outside Wuhan, China. JAMA 2020;323(11):1092-1093

10 Lai CC, Shih TP, Ko WC, Tang HJ, Hsueh PR. Severe acute respiratory syndrome coronavirus 2 (SARS-CoV-2) and coronavirus disease-2019 (COVID-19): the epidemic and the challenges. Int J Antimicrob Agents 2020;55(3):105924

11 Mao L, Jin H, Wang M, et al. Neurologic manifestations of hospitalized patients with coronavirus disease 2019 in Wuhan, China. JAMA Neurol 2020. Doi: 10.1001/jamaneurol.2020.1127

12 Zhao H, Shen D, Zhou H, Liu J, Chen S. Guillain-Barré syndrome associated with SARS-CoV-2 infection: causality or coincidence? Lancet Neurol 2020;19(5):383-384

13 Chung M, Bernheim A, Mei X, et al. CT imaging features of 2019 novel coronavirus (2019-nCoV) Radiology 2020;295(1): 202-207

14 Kanne JP. Chest CT findings in 2019 novel coronavirus (2019-nCoV) infections from Wuhan, China: key points for the radiologist. Radiology 2020;295(1):16-17

15 Soldati G, Smargiassi A, Inchingolo R, et al. Is there a role for lung ultrasound during the COVID-19 pandemic? J Ultrasound Med 2020. Doi: 10.1002/jum.15284

16 World Health Organization. Clinical management of severe acute respiratory infection (sari) when covid-19 disease is suspected: interim guidance. Available at: https:// www.who.int/publications-detail/clinical-management-ofsevere-acute-respiratory-infection-when-novel-coronavirus(ncov)-infection-is-suspected. Accessed May 19, 2020

17 Chu DK, Kim LH, Young PJ, et al. Mortality and morbidity in acutely ill adults treated with liberal versus conservative oxygen therapy (IOTA): a systematic review and meta-analysis. Lancet 2018;391(10131):1693-1705

18 Festic E, Bansal V, Kor DJ, Gajic O; US Critical Illness and Injury Trials Group: Lung Injury Prevention Study Investigators (USCIITG-LIPS). SpO2/FiO2 ratio on hospital admission is an indicator of early acute respiratory distress syndrome development among patients at risk. J Intensive Care Med 2015;30(4):209-216

19 Alhazzani W, Møller MH, Arabi YM, et al. Surviving Sepsis Campaign: guidelines on the management of critically ill adults with coronavirus disease 2019 (COVID-19). Intensive Care Med 2020;46(5):854-887

20 Frat JP, Thille AW, Mercat A, et al; FLORALI Study Group; REVA Network. High-flow oxygen through nasal cannula in acute hypoxemic respiratory failure. N Engl J Med 2015;372(23):2185-2196

21 Ni YN, Luo J, Yu H, Liu D, Liang BM, Liang ZA. The effect of highflow nasal cannula in reducing the mortality and the rate of endotracheal intubation when used before mechanical ventilation compared with conventional oxygen therapy and noninvasive positive pressure ventilation. A systematic review and meta-analysis. Am J Emerg Med 2018;36(2):226-233 
22 Lyons C, Callaghan M. The use of high-flow nasal oxygen in COVID-19. Anaesthesia 2020. Doi: 10.1111/anae.15073

23 Riera J, Pérez P, Cortés J, Roca O, Masclans JR, Rello J. Effect of high-flow nasal cannula and body position on end-expiratory lung volume: a cohort study using electrical impedance tomography. Respir Care 2013;58(4):589-596

24 Chandra D, Stamm JA, Taylor B, et al. Outcomes of noninvasive ventilation for acute exacerbations of chronic obstructive pulmonary disease in the United States, 1998-2008. Am J Respir Crit Care Med 2012;185(2):152-159

25 Chawla R, Dixit SB, Zirpe KG, et al. ISCCM guidelines for the use of non-invasive ventilation in acute respiratory failure in adult ICUs. Indian J Crit Care Med 2020;24(Suppl 1):S61-S81

26 Lucchini A, Giani M, Isgrò S, Rona R, Foti G. The "helmet bundle" in COVID-19 patients undergoing non invasive ventilation. Intensive Crit Care Nurs 2020. Doi: 10.1016/j.iccn.2020.102859

27 Yoshida T, Amato MBP, Kavanagh BP, Fujino Y. Impact of spontaneous breathing during mechanical ventilation in acute respiratory distress syndrome. Curr Opin Crit Care 2019;25(2):192-198

28 Cheyne WS, Gelinas JC, Eves ND. Hemodynamic effects of incremental lung hyperinflation. Am J Physiol Heart Circ Physiol 2018;315(3):H474-H481

29 Alraddadi BM, Qushmaq I, Al-Hameed FM, et al; Saudi Critical Care Trials Group. Noninvasive ventilation in critically ill patients with the Middle East respiratory syndrome. Influenza Other Respir Viruses 2019;13(4):382-390

30 Arabi YM, Arifi AA, Balkhy HH, et al. Clinical course and outcomes of critically ill patients with Middle East respiratory syndrome coronavirus infection. Ann Intern Med 2014;160(6):389-397

31 Meng L, Qiu H, Wan L, et al. Intubation and ventilation amid the COVID-19 outbreak: Wuhan's experience. Anesthesiology 2020;132(6):1317-1332

32 Gattinoni L, Coppola S, Cressoni M, Busana M, Rossi S, Chiumello D. Covid-19 does not lead to a "typical" acute respiratory distress syndrome. Am J Respir Crit Care Med 2020;201(10):1299-1300

33 Walkey AJ, Del Sorbo L, Hodgson CL, et al. Higher PEEP versus lower PEEP strategies for patients with acute respiratory distress syndrome. A systematic review and meta-analysis. Ann Am Thorac Soc 2017;14(Suppl 4):S297-S303

34 Alessandri F, Pugliese F, Ranieri VM. The role of rescue therapies in the treatment of severe ARDS. Respir Care 2018;63(1):92-101

35 Guérin C, Reignier J, Richard JC, et al; PROSEVA Study Group. Prone positioning in severe acute respiratory distress syndrome. N Engl J Med 2013;368(23):2159-2168

36 Bloomfield R, Noble DW, Sudlow A. Prone position for acute respiratory failure in adults. Cochrane Database Syst Rev 2015; (11):CD008095

37 Mora-Arteaga JA, Bernal-Ramírez OJ, Rodríguez SJ. The effects of prone position ventilation in patients with acute respiratory distress syndrome. A systematic review and metaanalysis. Med Intensiva 2015;39(6):359-372

38 Hong X, Xiong J, Feng Z, Shi Y. Extracorporeal membrane oxygenation (ECMO): does it have a role in the treatment of severe COVID-19? Int J Infect Dis 2020;94:78-80

39 Ramanathan K, Antognini D, Combes A, et al. Planning and provision of ECMO services for severe ARDS during the COVID-19 pandemic and other outbreaks of emerging infectious diseases. Lancet Respir Med 2020;8(5):518-526

40 Hariri G, Joffre J, Leblanc G, et al. Narrative review: clinical assessment of peripheral tissue perfusion in septic shock. Ann Intensive Care 2019;9(1):37

41 Fougères E, Teboul JL, Richard C, Osman D, Chemla D, Monnet $\mathrm{X}$. Hemodynamic impact of a positive end-expiratory pressure setting in acute respiratory distress syndrome: importance of the volume status. Crit Care Med 2010;38(3):802-807

42 Wiedemann HP, Wheeler AP, Bernard GR, et al; National Heart, Lung, and Blood Institute Acute Respiratory Distress Syndrome (ARDS) Clinical Trials Network. Comparison of two fluid-management strategies in acute lung injury. N Engl J Med 2006;354(24):2564-2575

43 Silversides JA, Major E, Ferguson AJ, et al. Conservative fluid management or deresuscitation for patients with sepsis or acute respiratory distress syndrome following the resuscitation phase of critical illness: a systematic review and meta-analysis. Intensive Care Med 2017;43(2):155-170

44 Brown SM, Pittman J, Miller Iii RR, et al. Right and left heart failure in severe $\mathrm{H} 1 \mathrm{~N} 1$ influenza $\mathrm{A}$ infection. Eur Respir J 2011;37(1):112-118

45 Paddock CD, Liu L, Denison AM, et al. Myocardial injury and bacterial pneumonia contribute to the pathogenesis of fatal influenza $B$ virus infection. J Infect Dis 2012;205(6):895-905

46 Kwong JC, Schwartz KL, Campitelli MA, et al. Acute myocardial infarction after laboratory-confirmed influenza infection. N Engl J Med 2018;378(4):345-353

47 Wang L, Li X, Chen H, et al. Coronavirus disease 19 infection does not result in acute kidney injury: an analysis of 116 hospitalized patients from Wuhan, China. Am J Nephrol 2020;51(5):343-348

48 Joannidis M, Forni LG, Klein SJ, et al. Lung-kidney interactions in critically ill patients: consensus report of the Acute Disease Quality Initiative (ADQI) 21 Workgroup. Intensive Care Med 2020;46(4):654-672

49 Fanelli V, Fiorentino M, Cantaluppi V, et al. Acute kidney injury in SARS-CoV-2 infected patients. Crit Care 2020;24(1):155

50 Simmons J, Ventetuolo CE. Cardiopulmonary monitoring of shock. Curr Opin Crit Care 2017;23(3):223-231

51 Arabi YM, Fowler R, Hayden FG. Critical care management of adults with community-acquired severe respiratory viral infection. Intensive Care Med 2020;46(2):315-328

52 Cao B, Wang Y, Wen D, et al. A trial of Lopinavir-Ritonavir in adults hospitalized with severe covid-19. N Engl J Med 2020;382(19):1787-1799

53 Grein J, Ohmagari N, Shin D, et al. Compassionate use of Remdesivir for patients with severe covid-19. N Engl J Med 2020. Doi: 10.1056/NEJMoa2007016

54 Luo P, Liu Y, Qiu L, Liu X, Liu D, Li J. Tocilizumab treatment in COVID-19: a single center experience. J Med Virol 2020. Doi: $10.1002 / j m v .25801$

55 Sanmartí R, Ruiz-Esquide V, Bastida C, Soy D. Tocilizumab in the treatment of adult rheumatoid arthritis. Immunotherapy 2018;10(6):447-464

56 Russell CD, Millar JE, Baillie JK. Clinical evidence does not support corticosteroid treatment for 2019-nCoV lung injury. Lancet 2020;395(10223):473-475

57 Mehta P, McAuley DF, Brown M, Sanchez E, Tattersall RS, Manson JJ; HLH Across Speciality Collaboration, UK. COVID-19: consider cytokine storm syndromes and immunosuppression. Lancet 2020;395(10229):1033-1034

58 Cortegiani A, Ingoglia G, Ippolito M, Giarratano A, Einav S. A systematic review on the efficacy and safety of chloroquine for the treatment of COVID-19. J Crit Care 2020;57:279-283

59 Shen C, Wang Z, Zhao F, et al. Treatment of 5 critically ill patients with COVID-19 with convalescent plasma. JAMA 2020;323(16):1582-1589

60 Zhou N, Pan T, Zhang J, et al. Glycopeptide antibiotics potently inhibit cathepsin $\mathrm{L}$ in the late endosome/lysosome and block the entry of Ebola virus, Middle East Respiratory Syndrome Coronavirus (MERS-CoV), and Severe Acute Respiratory Syndrome Coronavirus (SARS-CoV) J Biol Chem 2016;291(17):9218-9232 
61 Bacharier LB, Guilbert TW, Mauger DT, et al. Early administration of azithromycin and prevention of severe lower respiratory tract illnesses in preschool children with a history of such illnesses: a randomized clinical trial. JAMA 2015;314(19):2034-2044

62 Gautret P, Lagier JC, Parola P, et al. Hydroxychloroquine and azithromycin as a treatment of COVID-19: results of an open-label non-randomized clinical trial. Int J Antimicrob Agents 2020. Doi: 10.1016/j.ijantimicag.2020.105949

63 Iba T, Levy JH, Warkentin TE, Thachil J, van der Poll T, Levi M; Scientific and Standardization Committee on DIC, and the Scientific and Standardization Committee on Perioperative and Critical Care of the International Society on Thrombosis and Haemostasis. Diagnosis and management of sepsis-induced coagulopathy and disseminated intravascular coagulation. J Thromb Haemost 2019;17(11):1989-1994
64 Tang N, Bai H, Chen X, Gong J, Li D, Sun Z. Anticoagulant treatment is associated with decreased mortality in severe coronavirus disease 2019 patients with coagulopathy. J Thromb Haemost 2020;18(5):1094-1099

65 Kaiying Y, Hanping S. Interpretation of expert recommendations on medical nutrition therapy for patients with new coronavirus pneumonia. Nat Med J China 2020;100:724-728

66 Romano L, Bilotta F, Dauri M, et al. Medical nutrition therapy for critically ill patients with covid19. Eur Rev Med Pharmacol Sci 2020;24(7):4035-4039

67 Grasselli G, Pesenti A, Cecconi M. Critical care utilization for the COVID-19 outbreak in Lombardy, Italy: early experience and forecast during an emergency response. JAMA 2020. Doi: $10.1001 /$ jama.2020.4031 